Anton Friedrich Koch

\title{
Hermeneutischer Realismus
}

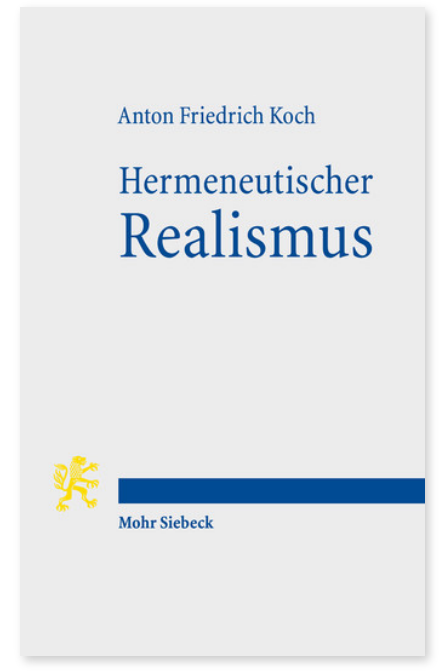

2016. VII, 178 Seiten.

ISBN 978-3-16-154433-0

DOI 10.1628/978-3-16-154433-0

eBook PDF $24,00 €$

ISBN 978-3-16-154377-7

fadengeheftete Broschur 24,00
Anton Friedrich Koch begründet und entwickelt in diesem Werk mit Mitteln der analytischen Philosophie einen hermeneutischen Realismus: die philosophische Lehre, dass das Reale zwar von einzelnen Meinungen und Wahrnehmungen unabhängig ist, nicht aber davon, dass es überhaupt Meinungen und Wahrnehmungen gibt. Wir, die endlichen, raumzeitlich verkörperten Subjekte, sind also kein Zufall, sondern notwendig für die Existenz des materiellen Raum-Zeit-Systems, das uns andererseits weiträumig umgibt und keineswegs unsere Konstruktion oder Fiktion ist (Subjektivitätsthese). Hermeneutisch ist dieser Realismus, weil er das Erkennen als einen Sonderfall des Lesens und Übersetzens - der Dinge in Wortsprache - begreift (Lesbarkeitsthese) und weil er der Entdeckung Raum gibt, dass Vollständigkeit und Widerspruchsfreiheit, wie in der Mathematik, so auch in der Weltbeschreibung unverträglich sind (Antinomiethese).

Anton Friedrich Koch Geboren 1952 in Gießen; Studium der Philosophie und Germanistik; 1980 Promotion in Heidelberg: 1989 Habilitation in München; 1993-96 Professor für Geschichte der Philosophie in Halle; 1996-2009 Professor für Philosophie in Tübingen; seit 2008 Mitglied der Heidelberger Akademie der Wissenschaften; seit 2009 Professor für Philosophie an der Universität Heidelberg.

Jetzt bestellen:

https://mohrsiebeck.com/buch/hermeneutischer-realismus-9783161544330?no_cache=1

order@mohrsiebeck.com

Telefon: $+49(0) 7071-923-17$

Telefax: $+49(0) 7071-51104$ 